\title{
A Model of Consumer Goods Characteristics
}

George W. Ladd; Veraphol Suvannunt

American Journal of Agricultural Economics, Vol. 58, No. 3. (Aug., 1976), pp. 504-510.

Stable URL:

http://links.jstor.org/sici?sici=0002-9092\%28197608\%2958\%3A3\%3C504\%3AAMOCGC\%3E2.0.CO\%3B2-0

American Journal of Agricultural Economics is currently published by American Agricultural Economics Association.

Your use of the JSTOR archive indicates your acceptance of JSTOR's Terms and Conditions of Use, available at

http://www.jstor.org/about/terms.html. JSTOR's Terms and Conditions of Use provides, in part, that unless you have obtained prior permission, you may not download an entire issue of a journal or multiple copies of articles, and you may use content in the JSTOR archive only for your personal, non-commercial use.

Please contact the publisher regarding any further use of this work. Publisher contact information may be obtained at http://www.jstor.org/journals/aaea.html.

Each copy of any part of a JSTOR transmission must contain the same copyright notice that appears on the screen or printed page of such transmission.

The JSTOR Archive is a trusted digital repository providing for long-term preservation and access to leading academic journals and scholarly literature from around the world. The Archive is supported by libraries, scholarly societies, publishers, and foundations. It is an initiative of JSTOR, a not-for-profit organization with a mission to help the scholarly community take advantage of advances in technology. For more information regarding JSTOR, please contact support@ jstor.org. 


\title{
A Model of Consumer Goods Characteristics
}

\author{
George W. Ladd and Veraphol Suvannunt
}

\begin{abstract}
This paper derives and tests two hypotheses concerning characteristics of purchased consumer goods. One hypothesis states retail price paid is a weighted linear combination of a product's yields of characteristics, each weight being a marginal implicit price of a characteristic. The second hypothesis expresses consumer demand for a product as a function of income, product prices, and product's yields of characteristics. Statistical results are consistent with the hypotheses. One model used in this paper is the consumer goods counterpart to the model used by Ladd and Martin in studying prices and demands for input characteristics.
\end{abstract}

Key words: hedonic prices, product characteristics, quality.

In a study carried out nearly fifty years ago, Waugh concluded, "There is a distinct tendency for market prices of many commodities to vary with certain physical characteristics which the consumer identifies with quality, and the relation of these characteristics to prices may in many cases be fairly accurately determined by statistical analysis. If this generalization is accepted as true, it opens up a field in the theory of prices which has been practically untouched" (1929, p. 87). This paper deals with this "field in the theory of prices" by developing a model-the consumer goods characteristics model (CGCM)-that yields the two hypotheses that are the themes of this paper. These are: for each product consumed, the price paid by the consumer equals the sum of the marginal monetary values of the product's characteristics; the marginal monetary value of each characteristic equals the quantity of the characteristic obtained from the marginal unit of the product consumed multiplied by the marginal implicit price of the characteristic (theme 1), and consumer demand functions for goods are affected by characteristics of the goods (theme 2).

The CGCM looks upon a product as a collection of characteristics. Product heterogene-

George W. Ladd is a professor of economics at Iowa State University, Ames, and Veraphol Suvannunt is in the Department of Business Economics in the Ministry of Commerce of Thailand.

Journal Paper No. J-8341 of the Iowa Agriculture and Home Economics Experiment Station, Ames, Iowa, Project No. 1906. This paper is partly a condensation and partly an extension of Suvannunt's thesis. The authors are grateful to the editors and anonymous referees for their helpful comments. ity arises because different products contain different kinds, different amounts, or both of various characteristics. CGCM is therefore useful for studying issues involving product heterogeneity such as product differentiation, quality, and grades and standards.

After developing the hypotheses stated in themes 1 and 2, all available statistical evidence is summarized. Then a number of applications are discussed. (Themes 1 and 2 refer to consumer goods. Two similar themes that apply to production inputs are discussed by Ladd and Martin.)

\section{Theoretical Model}

Products are wanted because of the utilities they provide. The utilities provided depend upon the product characteristics. Hence, the total amount of utility a consumer enjoys from his purchases of products depends upon the total amounts of product characteristics purchased. Let $x_{0 j}$ be the total amount of the $j$ th product characteristic provided to the consumer by consumption of all products. Let $x_{i j}$ be the quantity of the $j$ th characteristic provided by one unit of product $i$. For example, $x_{i j}$ might measure the length of an automobile, the presence or absence of an automatic transmission, or the amount of preparation time saved by using a TV dinner. Let $q_{i}$ represent the quantity of the $i$ th product consumed. Suppose we have $n$ products and each of the first $m$ product characteristics is provided by 
several products, but each product also provides a unique characteristic provided by no other product. Then total consumption of each characteristic can be expressed as a function of quantities of products consumed and of consumption input-output coefficients:

$$
\begin{gathered}
x_{0 j}=f_{j}\left(q_{1}, q_{2}, \ldots, q_{n}, x_{1 j},\right. \\
\left.x_{2 j}, \ldots, x_{n j}\right) \text { for } j=1,2, \ldots, m,
\end{gathered}
$$

and

$$
x_{0 m+i}=f_{m+i}\left(q_{i}, x_{i m+i}\right)
$$

for $i=1,2, \ldots, n$.

The consumer's utility function is expressed as

$$
U=U\left(x_{01}, x_{02}, \ldots,\right.
$$

Because each $x_{0 j}$ is a function of the $q_{i}^{\prime}$ s and the $x_{i j}$ s,

$$
\begin{array}{r}
U=U\left(q_{1}, q_{2}, \ldots, q_{n}, x_{11}, x_{12}, \ldots,\right. \\
\left.x_{1 m}, x_{21}, \ldots, x_{n m}, \ldots, x_{n m+n}\right) .
\end{array}
$$

It is assumed that the consumer can vary only the $q_{i}^{\prime}$ 's. The magnitudes of the $x_{i j}$ 's are parameters to the consumer; their magnitudes are determined by producers.

The consumer is assumed to maximize equation (2) subject to the budget constraint

$$
\sum_{i} p_{i} q_{i}=I,
$$

where $p_{i}$ is the fixed price paid for the $i$ th product, and $I$ is the consumer's fixed money income, that is, the consumer selects the values of the $q_{i}$ that maximize the Lagrangian

(5) $L=U\left(x_{01}, x_{02}, \ldots, x_{0 m+n}\right)$

$$
-\lambda\left(\sum_{i} p_{i} q_{i}-I\right)
$$

The consumer is viewed as selecting the combination of products that provides the combination of total product characteristics that maximizes utility. Choices of products are based on their different characteristics. Because the $x_{0 j}$ 's are functions of the $q_{i}$ 's, compound function (function of a function) rules for differentiating $U$ must be used:

$$
\begin{aligned}
\partial L / \partial q_{i}= & 0=\sum_{j}\left(\partial U / \partial x_{0 j}\right)\left(\partial x_{0 j} / \partial q_{i}\right) \\
& +\left(\partial U / \partial x_{0 m+i}\right)\left(\partial x_{0 m+i} / \partial q_{i}\right)-\lambda p_{i} .
\end{aligned}
$$

To assure a unique maximum, the Hessian of $U$ is assumed negative definite and the bordered Hessian of $L$ is assumed negative semidefinite.

The marginal utility of income is $\lambda: \lambda=$ $\partial U / \partial I$. Substituting this expression into equation (6) and solving for $p_{i}$ yields

$$
\begin{aligned}
p_{i}= & \sum_{j}\left(\partial x_{0 j} / \partial q_{i}\right)\left[\left(\partial U / \partial x_{0 j}\right) /(\partial U / \partial I)\right] \\
& +\left(\partial x_{0 m+i} / \partial q_{i}\right)\left[\left(\partial U / \partial x_{0 m+i}\right) /(\partial U / \partial I)\right] .
\end{aligned}
$$

The marginal yield of the $j$ th product characteristic by the $i$ th product is $\partial x_{0 j} / \partial q_{i}$, e.g., the amount of protein per pound of a particular steak. The marginal yield of the $i$ th product's unique characteristic is $\partial x_{0 m+i} / \partial q_{i}$. In the bracketed terms, $\partial U / \partial x_{0 j}$ is the marginal utility of the $j$ th product characteristic, and $\partial U / \partial I$ is the marginal utility of income. Their ratio is the marginal rate of substitution between income and the $j$ th product characteristic. By equation (4), income equals total expenditure. Therefore, the bracketed term can be interpreted as the marginal rate of substitution between expenditure and the $j$ th product characteristic, that is, as the (marginal) implicit or imputed price paid for the $j$ th product characteristic. For convenience, write $\left(\partial U / \partial x_{0 j}\right) /$ $(\partial U / \partial I)=\partial I / \partial x_{0 j}=\partial E / \partial x_{0 j}$, where $E=$ total expenditure on all products. Assume each unit of each product supplies one unit of its own unique characteristic. Then, $\partial x_{0 m+i} / \partial q_{i}=1$, and equation (7) becomes

$$
p_{i}=\sum_{j}\left(\partial x_{0 j} / \partial q_{i}\right)\left(\partial E / \partial x_{0 j}\right)+\partial E / \partial x_{0 m+i}
$$

Equation (8) states theme 1.

Equations (4) and (6) provide a system of $n+1$ equations in the $n+1$ unknowns $\lambda, q_{1}$, $q_{2}, \ldots, q_{n}$, and the knowns $I, p_{1}, p_{2}, \ldots, p_{n}$, $x_{11}, x_{12}, \ldots, x_{n m+n}$. Solving these equations provides the maximizing values of $\lambda$ and of consumption, say, $\lambda^{*}, q_{1^{*}}, q_{2^{*}}, \ldots, q_{n^{*}}$. The effect of change in price $p_{s}$ upon $q_{r^{*}}$ is given by the well-known expression $\partial q_{r^{*}} / \partial p_{s}=$ $-q_{s} \partial q_{r} / \partial I+S_{s r}$, where $S_{s r}=$ the SlutskyHicks-Allen substitution term. Assume the producer of product $u$ makes a small change in $x_{u v}$, while all other $x_{i j}$ 's, all prices, and income remain constant. ${ }^{1}$ By differentiating equations (4) and (6) with respect to $x_{u v}$, and manipulating, one obtains

$$
\text { (9) } \partial q_{r^{*}} / \partial x_{u v}=-\left(1 / \lambda^{*}\right) \sum_{i=1}^{n}\left(\partial U_{i} / \partial x_{u v}\right) S_{i r} \text {, }
$$

where $U_{i}=\partial U / \partial q_{i}$. The change in $q_{r^{*}}$ resulting from a change in composition of product $u$ depends upon the effects of the change in

${ }^{1}$ Product $u$ is a slightly different product after this change from what it was before the change. Before the change, the quantities of characteristics per unit of product $u$ were $x_{u 1}, x_{u 2}, \ldots, x_{u v-1}, x_{u v}$, $x_{u v+1}, \ldots, x_{u n}$. Afterwards, they are $x_{u 1}, x_{u 2}, \ldots, x_{u v-1}, x_{u v}+d x_{u v}$, $x_{u v+1}, \ldots, x_{u n}$. 
composition upon marginal utilities and upon substitution terms. Thus, the change in demand for product $r$ as $x_{u r}$ changes depends upon product $r$ 's complementarity or substitutability with other goods. Hence, the consumer's purchases of product $r$ can vary even though his income and product prices remain constant, provided that producers vary at least one consumption input-output coefficient.

Assume that $\partial U_{u} / \partial x_{u v}>0$ but $\partial U_{i} / \partial x_{u v}=0$ for $i \neq u$, i.e., increasing the amount of characteristic $v$ in product $u$ increases the marginal utility of product $u$ but leaves other marginal utilities unaffected. Then, from equation (9),

$$
\partial q_{r^{*}} / \partial x_{u v}=\left(-1 / \lambda^{*}\right)\left(\partial U_{u} / \partial x_{u v}\right) S_{u r} .
$$

If products $u$ and $r$ are substitutes $\left(S_{u r}>0\right)$, increasing the value of $x_{u v}$ reduces the demand for product $r$. If the two products are complements $\left(S_{u r}<0\right)$, increasing $x_{u v}$ increases the demand for product $r$. Setting $r=u$ in equation (10) yields

(11) $\partial q_{u^{*}} / \partial x_{u v}=\left(-1 / \lambda^{*}\right)\left(\partial U_{u} / \partial x_{u v}\right) S_{u u}>0$.

Equations (9), (10), and (11) provide the hypothesis stated in theme 2 .

\section{Comparison with Lancaster's Analysis}

Recently Lancaster used the product characteristics concept in his activity analysis of consumer behavior. He formulated the consumers' utility maximization problem as ( $\mathrm{p}$. 21)

$$
\begin{aligned}
& \max U(X) \text { subject to } P^{\prime} Q \leq I, \\
& B Q=X, X \geq 0, \text { and } Q \geq 0 .
\end{aligned}
$$

$X$ is a vector of quantities of characteristics, $Q$ and $P$ are vectors of quantities and prices of products, and $B$ is the consumption technology matrix of input-output coefficients. The $i$ th row of $B Q=X$ can be written as

$$
\sum_{j} b_{i j} q_{j}=x_{0 i}
$$

where $b_{i j}=$ the quantity of the $i$ th characteristic in one unit of product $j$, and $q_{j}$ and $x_{0 i}$ are as defined previously in CGCM. The rules for deriving the dual to this problem are discussed by various writers, among whom are Sengupta and Fox. Applying these rules leads to $n$ dual constraints (one for each product) of the form

$$
p_{j} \geq \sum_{i} b_{i j} z_{i} \text { for } z_{i} \text { unrestricted in sign. }
$$

This corresponds closely to equation (8), since $b_{i j}$ corresponds to $\partial x_{0 i} / \partial q_{j}$ and $z_{i}$ corresponds to the marginal implicit price of characteristic $i$. Lancaster did not derive equation (14) from his general activity analysis model. But he did derive equation (14) from a special expenditure minimizing linear program.

Others who have used the product characteristics concept without, however, developing themes 1 and 2 are Theil and the workers in the hedonic price index area (see Griliches, Adelman and Griliches, Dhrymes). These writers use the utility function equation (3). They are prevented from deriving themes 1 and 2 by their assumption that the magnitudes of the $x_{i j}$ 's and the $q_{i}^{\prime}$ 's are determined by the consumer. The $x_{i j}$ 's are treated here as parameters to the consumer and variables to producers. The consumer can decide how much of product $i$ to buy; he cannot however decide the amount of each characteristic to be contained in or provided by one unit of product $i$.

Three reviews of Lancaster's model have recently been published (Hendler, Lucas, Ratchford). Lucas questions Lancaster's assumption of a linear consumption technology, equation (13). This criticism does not apply to CGCM; compare equation (13) with equation (1). Hendler discusses limitations arising from Lancaster's assumption that marginal utilities of all characteristics are nonnegative. We do not make this assumption; any $\partial U / \partial x_{0 j}$ 's in equation (6) may be negative. Both Lucas and Hendler seriously question Lancaster's assumption that utility depends only upon total quantities of characteristics and not upon their distribution among commodities. This criticism does apply to CGCM. Themes 1 and 2 can be derived from a variation of CGCM to which none of these three criticisms apply. Define $t_{i j}$ as the total quantity of characteristic $j$ obtained from total consumption of product $i$. Then $x_{0 j}=\sum_{i} t_{i j}$. In this variation of CGCM, the arguments of the utility function are the variables $x_{0 j}$ 's and the ratios $x_{0 j} / t_{i j}$ 's. But since the $x_{0 j}$ 's are functions of the $t_{i j}$ 's, the utility function can be expressed simply as a function of the $t_{i j}$ 's. The statement of theme 1 derived from this model is exactly like equation (8) except that $t_{i j}$ replaces $x_{0 j}$. The statement of theme 2 is exactly like equation (9).

\section{Empirical Tests}

Equation (8) provides the hypothesis that for each product purchased by the consumer, the 
price he pays can be expressed as the sum of the products of marginal yields of characteristics and ratios of marginal utilities. We have called these latter ratios marginal implicit prices. All of the data seen on yields of product characteristics are consistent with the assumption that $\partial x_{0 j} / \partial q_{i}=x_{i j}=$ constant. Assuming this and assuming $\partial E / \partial x_{0 j}=E_{j}=$ constant, equation (8) can be written as

$$
p_{i}=\sum_{i} x_{i j} E_{j}+E_{m+i} \text {. }
$$

Regressing product prices upon product characteristics (as measured by $x_{i j}$ ) provides a test of the hypothesis that $p_{i}$ is linearly related to the $x_{i j}$ 's. If $\partial E / \partial x_{0 j}$ is not believed constant, one might use

$$
p_{i}=\sum_{j} x_{i j} \beta_{j}+\sum_{j} x_{i j}^{2} \beta_{j j}
$$

and determine marginal implicit price, say, for characteristic $h$, as $\partial E / \partial x_{0 h}=E_{h}=\beta_{h}$ $+\beta_{h h} x_{i h}$. Hedonic price workers generally have used logarithmic equations $\left(p_{i}=\pi x_{j} x^{\beta_{j}}\right)$ or semilogarithmic equations $\left(p_{i}=\exp \left(\Sigma x_{i j} \beta_{j}\right)\right)$ to relate product prices to product characteristics. Neither of these forms is consistent with equation (8); they cannot be interpreted as relating product price to the sum of the products of marginal yields of characteristics and marginal implicit prices.

Dhrymes applies equation (15) to U.S. automobile prices. He found that a large proportion of the variance in U.S. automobile prices could be explained by a linear combination of automobile length, width, brake horsepower, number of cylinders, number of doors, and presence or absence of automatic transmission and power steering. Cowling and Cubbin found that a large proportion of variance in U.K. automobile prices could be explained by a linear combination of automobile characteristics.

Waugh $(1928,1929)$ estimated relations between wholesale prices of fresh vegetables and their characteristics. He collected data on wholesale prices and characteristics of individual lots of asparagus, tomatoes, and cucumbers. He regressed the ratio of the price of each lot to the average price of the product on measures of product characteristics and converted the regression coefficients into prices of product characteristics. For example, from his analysis of prices of asparagus, he concluded that $(a)$ each additional inch of green color per stalk added $38.45 \propto$ to the price of one dozen standard bunches, $(b)$ each addi- tional stalk per bunch reduced price by $4.6 c$, and $(c)$ each additional percentage variation in size of stalk decreased price by $0.76 \notin$ per dozen standard bunches. ${ }^{2}$ For asparagus and tomatoes he used a linear equation, like equation (15). For cucumbers, he used a nonlinear relation, like equation (16).

In these studies, the values of the $x_{i j}$ 's were fairly easily determined, either by inspection or by studying manufacturer's specifications. We performed a more rigorous test of equation (8), more rigorous because the characteristics are not easily identified and measured. The linear form was used to relate annual average retail prices of thirty-one different meat, dairy, and poultry items to amounts of various nutritional elements they provided per pound.

Table 1 lists the thirty-one food items. Their national annual average retail prices per pound for 1969 and 1970 were obtained from U.S. Bureau of Labor Statistics reports. Amounts of sixteen different nutritional elements per pound of each food were obtained from Watt and Merrill. These sixteen elements and their units of measurement are identified in table 2 .

Suppose that one's sample contains one observation on each of $n$ products and these products contain $m$ common characteristics, that is, each of the $m$ common characteristics is possessed by two or more of the $n$ products. Then it is not possible to estimate a separate price for each common characteristic and each product's unique characteristic because the number of coefficients to be estimated exceeds the number of observations. The number of observations is $n$ but the number of coefficients is $n+m, m$ coefficients for the prices of common characteristics plus $n$ coefficients for the prices of unique characteristics. To handle this degrees-of-freedom problem, we imposed restrictions on the prices of unique characteristics. First, the prices of unique characteristics are assumed to be the same for every product. With the requirement that $E_{m+i}$ $=E_{17}$ for all $i$, the following equation was estimated:

$$
\begin{aligned}
& p_{i}=\sum_{j=1}^{16} x_{i j} E_{j}+E_{17}+\epsilon_{i} \\
& \quad \text { for } i=1,2, \ldots, 31 .
\end{aligned}
$$

In this form several pairs of the independent variables were highly intercorrelated. After eliminating one variable of each of these pairs

\footnotetext{
${ }^{2}$ Although equation (8) refers to retail prices and Waugh studied wholesale prices, his results are consistent with theme 1 because wholesale and retail prices are highly positively correlated.
} 
Table 1. Thirty-one Food Items Used in Estimation

Item $i$

1. Round steak

2. Sirloin steak

3. Porterhouse steak

4. Boneless rump roast

5. Rib roast

6. Chuck roast

7. Hamburger

8. Beef liver

9. Veal cutlets

10. Pork chops

11. Loin roast

12. Pork sausage

13. Whole ham

14. Picnic ham

15. Bacon

16. Lamb chop

17. Frankfurters

18. Canned ham

19. Bologna sausage

20. Salami sausage

21. Liver sausage

22. Frying chicken

23. Chicken breasts

24. Eggs

25. Grocery fresh milk

26. Delivery fresh milk

27. Skim fresh milk

28. Evaporated milk

29. Ice cream

30. American process cheese

31. Butter

and eliminating other variables with small $t$-ratios, the results in the second and third columns of table 3 are obtained.

Next, the price of uniqueness was assumed to be a function of raw material source and the following equation was estimated:

$$
p_{i}=\sum_{j} x_{i j} E_{j}+E_{i}+\epsilon_{i},
$$

where $E_{i}=E_{B}$ for food items 1 through 8, beef; $E_{i}=E_{V}$ for item 9, veal cutlets; $E_{i}=E_{H}$ for items 10 through 15 , pork; $E_{i}=E_{L}$ for item 16 , lamb chops; $E_{i}=E_{P M}$ for items 17 through 21 , processed meats; $E_{i}=E_{P}$ for items 22 through 24 , poultry products; and $E_{i}=E_{D}$ for items 25 through 31 , dairy products. Analysis of variance indicated that many of these $E_{i}$ were not significantly different from each other.

Finally, the products whose prices of uniqueness were not significantly different from each other were grouped together, and the following equation was estimated:

$$
p_{i}=\sum_{j} x_{i j} E_{j}+E_{i}+\epsilon_{i}
$$

where $E_{i}=E_{18}$ for all items except veal cutlets
Table 2. Nutritional welements and Their Units of Measurement

\begin{tabular}{clc}
\hline $\begin{array}{c}\text { Nutritional } \\
\text { Element } j\end{array}$ & \multicolumn{1}{c}{$\begin{array}{c}\text { Nutritional } \\
\text { Element }\end{array}$} & $\begin{array}{c}\text { Unit of Measurement of } \\
\text { Nutritional Element } \\
\text { (per pound) }\end{array}$ \\
\hline 1 & Water & $\%$ \\
2 & Food energy & $\mathrm{cal}$. \\
3 & Protein & $\mathrm{g}$. \\
4 & Fat & $\mathrm{g}$. \\
5 & Carbohydrate & $\mathrm{g}$. \\
6 & Ash & $\mathrm{g}$. \\
7 & Calcium & $\mathrm{mg}$. \\
8 & Phosphorous & $\mathrm{mg}$. \\
9 & Iron & $\mathrm{mg}$. \\
10 & Sodium & $\mathrm{mg}$. \\
11 & Potassium & $\mathrm{I} . \mathrm{U}$. \\
12 & Vitamin A value & $\mathrm{mg}$. \\
13 & Thiamine & $\mathrm{mg}$. \\
14 & Riboflavin & $\mathrm{mg}$. \\
15 & Niacin & $\mathrm{mg}$. \\
16 & Ascorbic acid &
\end{tabular}

and lamb chops, $E_{i}=E_{25}$ for veal cutlets, and $E_{i}=E_{32}$ for lamb chops. These results are presented in table 3. Equation (19) yielded a significantly larger value of $R^{2}$ than did equation (17) or (18). All three equations yielded significant values of $R^{2}$. Thus, all are consistent with theme 1 . Results in table 3 were obtained by pooling data for 1969 and 1970 because results of an $F$-test for equality of two sets of coefficients did not reject the hypothesis that the coefficients were equal in the two years.

We interpret $\hat{E}_{j}$ in table 3 as estimated implicit prices paid by consumers in 1969-70 for the nutritional elements identified in the first column. For example, $j=2$ identifies food energy measured in calories; $\hat{E}_{2}=0.026$ in equation (19) indicates the estimated implicit price of food energy was $0.026 \notin$ per calorie. Suppose there was some cut of beef that was like sirloin except that it contained one hundred more calories of food energy and ten more grams of protein per pound. Equation (19) predicts that the price of this cut of beef would have been $19 \mathfrak{c}$ per pound higher than the price of sirloin in 1969-70: 0.026(100) + $1.666(10)=19.26$.

Dhrymes and Cowling and Cubbin obtained negative coefficients for some automobile characteristics. Waugh obtained negative coefficients for some vegetable characteristics (1928, 1929); as mentioned earlier, he found a negative marginal implicit price of $4.6 \notin$ for number of stalks per bunch. Negative marginal implicit prices are consistent with CGCM 
Table 3. Estimated Equations for Implicit Prices for Nutritional Elements in Thirty-one Food Items, 1969-70

\begin{tabular}{|c|c|c|c|c|c|}
\hline \multirow[b]{2}{*}{$\begin{array}{l}\text { Nutritional } \\
\text { Element } j \\
\end{array}$} & \multicolumn{2}{|c|}{ Equation (17) } & \multicolumn{2}{|c|}{ Equation (19) } & \multirow[b]{2}{*}{$\begin{array}{c}\begin{array}{c}\text { Unit of } \\
\text { Measurement } \\
\text { of } \hat{E}_{j}\end{array} \\
\end{array}$} \\
\hline & $\begin{array}{c}\text { Regression } \\
\text { Coefficient } \hat{E}_{j}\end{array}$ & $\begin{array}{c}\text { Absolute Value } \\
\text { of } t \text {-ratio }\end{array}$ & $\begin{array}{c}\text { Regression } \\
\text { Coefficient } \hat{E}_{j}\end{array}$ & $\begin{array}{c}\text { Absolute } \\
\text { Value } \\
\text { of } t \text {-ratio }\end{array}$ & \\
\hline 2 , food energy & $0.022^{a}$ & 3.548 & 0.026 & 7.250 & e/cal. \\
\hline 3 , protein & 2.691 & 4.695 & 1.666 & 3.818 & e/g. \\
\hline 5 , carbohydrate & 0.017 & 0.059 & 0.074 & 0.404 & e/g. \\
\hline 8 , phosphorous & -0.127 & 3.791 & -0.077 & 3.080 & $\mathrm{e} / \mathrm{mg}$ \\
\hline 9 , iron & -5.329 & 2.379 & -1.539 & 0.886 & e/mg. \\
\hline 11 , potassium & 0.236 & 23.600 & 0.016 & 2.462 & $\mathrm{e} / \mathrm{mg}$ \\
\hline 14 , riboflavin & 26.197 & 2.740 & 11.085 & 1.550 & $\mathrm{e} / \mathrm{mg}$ \\
\hline 16 , ascorbic acid & -1.718 & 2.657 & -0.957 & 1.881 & $\mathrm{e} / \mathrm{mg}$ \\
\hline 17. & -7.873 & 0.474 & - & - & $c / \mathrm{lb}$ \\
\hline 18 & $-b$ & - & -8.307 & 0.779 & $\mathrm{e} / \mathrm{lb}$ \\
\hline 25 & - & - & 109.921 & 6.040 & $c / l b$ \\
\hline 32 & - & - & 67.270 & 3.246 & c/lb. \\
\hline$R^{2}$ & 0.624 & & 0.853 & & \\
\hline
\end{tabular}

a $\hat{E}_{j}$ is the estimate of $E_{j}$. Equation (19) has fifty degrees of freedom. For fifty degrees of freedom, critical levels of absolute values of $t$-ratios are 2.678 at $1 \%$ level, 2.008 at $5 \%, 1.658$ at $10 \%, 1.300$ at $20 \%$, and 0.681 at $50 \%$.

b Dash indicates not estimated.

and with observation. Some product characteristics are undesirable. Adding more of one of these characteristics to a product reduces its value to consumers. We do not know why $\hat{E}_{8}$ and $\hat{E}_{16}$, the marginal implicit prices for phosphorous and ascorbic acid, are negative. Two hypothetical explanations are $(a)$ phosphorous and ascorbic acid impart an unpleasant taste, texture, or odor and $(b)$ they are proxies for some characteristic that degrades taste, texture, or odor.

These four statistical studies are the only ones we know of that bear on theme 1 . The results of all four are consistent with the theme.

The multiple regression method used in these studies is not the only available method for estimating prices of nutritional elements. The shadow prices in duals of programming models of human diets also provide estimates of implicit prices of nutritional elements (see Smith 1959, 1963 for discussion).

Equation (9) presents the hypothesis that consumer demand for a product is related to the characteristics of the product as well as to prices and income. Four studies have tested this hypothesis; all have confirmed it. In a study of demand for beer, Stone tested and accepted the hypothesis that ". . . if stronger, and to that extent better, beer is obtainable at a given price, then more beer will be drunk" (p. 180). Brems found that the ratio between registrations of new Fords and new Chev- rolets was significantly positively related to the ratio of their brake horsepower. The Cowling and Cubbin study of the U.K. automobile market found automobile demand to be related to automobile characteristics. Harrington and Gislason found that retail sales of peaches were affected by peach color, retail sales of apricots were affected by color, defects, and hardness, and retail cherry sales were affected by ripeness of cherries. All four studies are consistent with theme 2 .

\section{Summary and Conclusions}

The first theme of this paper is that for each product consumed, the price paid for the product equals the sum of the marginal monetary values of the product's characteristics. The marginal monetary value of each characteristic equals the product's marginal yield of the characteristic multiplied by the marginal implicit price of the characteristic. This theme is derived in three different ways: from Lancaster's analysis, in CGCM, whose assumptions are less restrictive than Lancaster's, and in a third model whose assumptions are less restrictive than those of CGCM. Results of all relevant statistical analyses are consistent with the theme. One practical use of this theme is in use of marginal implicit prices to evaluate grading schemes for consumer products. Ladd and Martin used a model similar to 
CGCM to evaluate the present U.S. corn grading system.

The second theme of this paper is that consumer demands are affected by characteristics of goods. This theme was derived from CGCM and from another model. Results of statistical studies are consistent with this theme. One practical application of this theme is in product design. If the relation of consumer's purchases to product characteristics is known, a product can be designed to maximize profit by determining how much of each characteristic to put into the product. Dorfman and Steiner analyze the problem of optimal product design for a product having one variable characteristic. Ladd and Martin analyze the problem for a product having several variable characteristics.

CGCM has implications for the definition and measurement of product quality. It leads to the same conclusion that Southworth presented when he wrote, "Webster's first definition of 'quality' makes it synonymous with 'characteristic.' Quality meaning 'superior quality' is a derived or secondary meaning. Quality, then, need not be ordinal-good, better, best. It may only be different"' (p. 1385).

Consideration of CGCM leads naturally to the idea that we measure a product's characteristics in order to measure its quality. In doing this we replace the idea of "product quality" by "product qualities" and measure "qualities" by measuring characteristics. This recognizes that it may not be possible to rank two similar products according to their quality. It may be that product $A$ is of higher quality than product $B$ according to one characteristic but of lower quality according to a second characteristic. Then all we can say is that $\mathrm{A}$ and $\mathrm{B}$ are of different quality.

\section{[Received January 1975; revision accepted February 1976.]}

\section{References}

Adelman, Irma, and Zvi Griliches. "On an Index of Quality Change.' J. Amer. Statist. Ass. 56 (1961):535-48.

Brems, Hans. Product Equilibrium Under Monopolistic Competition. Cambridge: Harvard University Press, 1951.

Cowling, K., and J. Cubbin. "Price, Quality and Advertising Competition: An Econometric Analysis of the U.K. Car Market."'Economica 38 (1971):378-94.
Dhrymes, Phoebus J. "Price and Quality Changes in Consumer Capital Goods: An Empirical Study." Price Indexes and Quality Change, ed. Zvi Griliches, pp. 88-149. Cambridge: Harvard University Press, 1971.

Dorfman, Robert, and Peter Steiner. "Optimal Advertising and Optimal Quality." Amer. Econ. Rev. 44 (1954):826-36.

Griliches, Zvi, ed. Price Indexes and Quality Change. Cambridge: Harvard University Press, 1971.

Harrington, A. H., and Conrad Gislason. "Demand and Quality Preferences for Deciduous Fruits.' J. Farm Econ. 38 (1956): 1405-14.

Hendler, Reuven. "Lancaster's New Approach to Consumer Demand and Its Limitations." Amer. Econ. Rev. 65 (1975): 194-200.

Ladd, George W., and Marvin B. Martin. "Prices and Demand for Input Characteristics." Amer. J. Agr. Econ. 58 (1976):21-30.

Lancaster, Kelvin. Consumer Demand: A New Approach. New York: Columbia University Press, 1971.

Lucas, Robert E. B. "Hedonic Price Functions." Econ. Inq. 13 (1975): 157-78.

Ratchford, Brian T. "The New Economic Theory of Consumer Behavior: An Interpretative Essay." $J$. Consum. Res. 2 (1975):65-75.

Sengupta, Jati K., and Karl A. Fox. Optimization Techniques in Quantitative Economic Models. Amsterdam: North-Holland Publishing Co., 1969.

Smith, Victor E. Electronic Computation of Human Diets. Bur. of Bus. and Econ. Res., Grad. School of Bus. Admin., Michigan State University, East Lansing, 1963.

. "Linear Programming Models for the Determination of Palatable Human Diets." J. Farm Econ. 41 (1959):272-83.

Southworth, Herman M. "Discussion: The Function of Grades in an Affluent, Standardized-Quality Economy." J. Farm Econ. 43 (1961):1384-87.

Stone, Richard. The Measurement of Consumers' Expenditure and Behavior in the United Kingdom 1920-38. Vol. I. Cambridge: Cambridge University Press, 1954.

Suvannunt, Veraphol. "Measurement of Quantities and Prices of Product Qualities." Ph.D. thesis, Iowa State University, Ames, 1973.

Theil, Henri. "Qualities, Prices and Budget Enquiries." Rev. Econ. Stud. 19 (1952-53):129-47.

U.S. Bureau of Labor Statistics. Estimated Retail Food Prices by Cities: 1969 Annual Averages and 1970 Annual Averages. Washington, 1970 and 1971.

Watt, B. K., and A. L. Merrill. Composition of Foods: Raw, Processed, Prepared. USDA, Agr. Res. Serv., Agr. Handbook 8, 1963.

Waugh, Frederick V. Quality as a Determinant of Vegetable Prices. New York: Columbia University Press, 1929.

_. "Quality Factors Influencing Vegetable Prices." J. Farm Econ. 10 (1928):185-96. 
http://www.jstor.org

\section{LINKED CITATIONS \\ - Page 1 of 1 -}

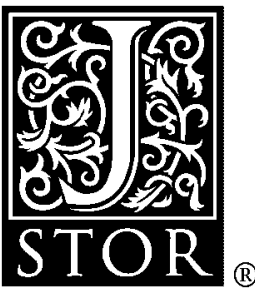

You have printed the following article:
A Model of Consumer Goods Characteristics
George W. Ladd; Veraphol Suvannunt
American Journal of Agricultural Economics, Vol. 58, No. 3. (Aug., 1976), pp. 504-510.
Stable URL:
http://links.jstor.org/sici?sici=0002-9092\%28197608\%2958\%3A3\%3C504\%3AAMOCGC\%3E2.0.CO\%3B2-0

This article references the following linked citations. If you are trying to access articles from an off-campus location, you may be required to first logon via your library web site to access JSTOR. Please visit your library's website or contact a librarian to learn about options for remote access to JSTOR.

\section{References}

Price, Quality and Advertising Competition: An Econometric Investigation of the United Kingdom Car Market

Keith Cowling; John Cubbin

Economica, New Series, Vol. 38, No. 152. (Nov., 1971), pp. 378-394.

Stable URL:

http://links.jstor.org/sici?sici=0013-0427\%28197111\%292\%3A38\%3A152\%3C378\%3APQAACA\%3E2.0.CO\%3B2-\%23 